\title{
PRODUCTION OF ARTHRITIS IN THYROPARATHYROIDECTOMIZED RAT BY INJECTIONS OF DEOXYCORTONE ACETATE
}

BY

\author{
R. G. HARRISON and T. J. BARNETT \\ From the Department of Anatomy, University of Liverpool
}

(RECEIVED FOR PUBLICATION AUGUST 27, 1953)

Selye and others (1944) claimed that certain "diseases of adaptation", including arthritis, nephrosclerosis, and periarteritis nodosa, could be produced in rats which are subjected to unilateral nephrectomy, injected with deoxycortone acetate (DCA) and given 1 per cent. saline to drink. Harrison (1946) was at first unable to produce arthritis in rats by these methods, and later (Harrison, 1951a) showed that the manner of removing the left kidney in the experiments is an important factor. If, during the operative removal of the left kidney, the inferior adrenal arteries arising from the renal artery are deliberately or inadvertently interrupted, an area of focal necrosis in the zona fasciculata of the ipsilateral adrenal cortex results (Harrison, 1951b). Experimental arthritis could only be produced by injections of DCA in rats possessing such a focal necrosis of the adrenal cortex. This experimental observation is interesting from the clinical viewpoint, since focal necrosis in the $\mathrm{z}$. fasciculata of the rat adrenal cortex might be expected to cause a primary reduction in the secretion of gluco-corticoids (including cortisone), and a dissociation of the normal relationships of gluco-corticoid and mineralocorticoid secretion, which would be enhanced by the DCA injections. This adrenal cortical relationship appears to be peculiar to arthritis only, and not to the other diseases of adaptation investigated (Harrison, 1952).

If this theory is correct, it should be possible to produce arthritis by injections of DCA in rats in which an atrophy of the $\mathrm{z}$. fasciculata of the adrenal cortex has been effected by other means. It was therefore decided to determine whether injections of DCA would induce arthritic changes in the thyroparathyroidectomized rat, since after this latter procedure not only is there an overall decrease in weight and size of the adrenals due to a fall in basal metabolic rate, but also the $z$. fasciculata atrophies markedly (Deane and Greep, 1947).

\section{Material and Methods}

In this experiment 24 immature female albino rats, varying in weight from 31 to $63 \mathrm{~g}$. were used. Littermates were divided equally into two groups. The mean body weight of rats in Group I was $41.5 \mathrm{~g}$., in Group II 43.9 g. Animals of both groups were subjected to thyroparathyroidectomy, while the left kidney in rats of Group II was simultaneously removed in addition, taking care not to damage the adrenal blood vessels or to handle the kidney unduly lest vasoconstriction should occur in the renal artery and possibly the inferior adrenal arteries. Removal of the thyroid in the rat necessitates removal of the parathyroids which are embedded in it; the small size of the thyroid and the microscopic size of the parathyroids effectively precludes any attempt at separating the latter and grafting them into the wound post-operatively. In addition to being given 1 per cent. saline to drink instead of tap-water throughout the experiment, all rats were therefore provided with powdered calcium lactate ad lib. on a tray throughout the post-operative period. All rats of both groups were fed on a diet similar in composition to "purina fox chow", and were kept in a thermostatically controlled animal house free from draughts at a temperature of $71^{\circ}$ to $85^{\circ} \mathrm{F}$. (Fig. 1). Commencing on the fifth day after operation, all rats of both groups were injected subcutaneously twice daily with $2 \mathrm{mg}$. DCA from an aqueous suspension containing $20 \mathrm{mg}$. DCA per $\mathrm{ml}$. and 0.1 per cent. cetrimide

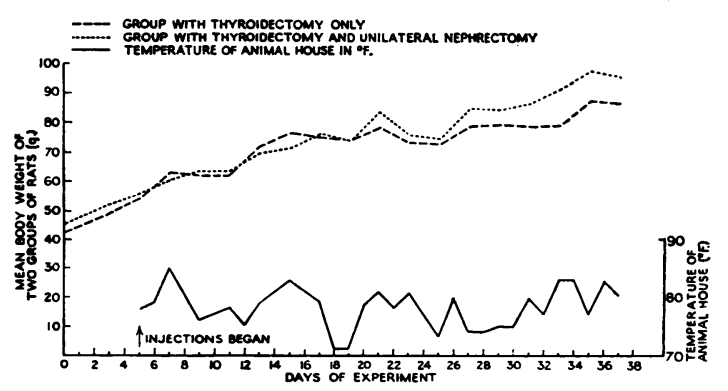

Fig. 1.-Mean body-weight gain in two groups of rats throughout experiment, and animal-house temperature. 
(Harrison, 1951a). Injections were continued until the 37 th day after operation, when all surviving rats were killed.

The experimental technique therefore provided two groups of rats given 1 per cent. saline to drink, injected with DCA, and fed on "purina fox chow" and calcium lactate: Group I, thyroparathyroidectomized, and Group II, thyroparathyroidectomized and unilaterally nephrectomized. By such methods it was hoped to determine whether arthritis could be produced by ablation of the thyroid, if atrophy of the $z$. fasciculata of the adrenal cortex is essential for the production of experimental arthritis, and whether removal of the left kidney without involving the adrenal blood supply is essential for, or helpful in, the production of arthritis.

The adrenals, kidneys, heart, hind feet, and lungs were removed at autopsy from all rats, fixed immediately, cut, and stained. The adrenals were fixed in formal calcium and treated with Sudan black for the detection of lipoids, or the acid haematein test (Baker, 1946) for phospholipids. The other tissues were fixed in Zenker-formol, and the joints embedded in low-viscosity nitrocellulose before sectioning.

\section{Results}

Two animals of Group I and three of Group II died during the night within the first 7 days after operation. Six other rats of Group II either died, or became moribund and were killed, on the 16th, 19th, 21 st (two rats), 25th, and 30th days after operation,

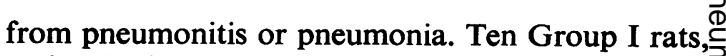
and only three Group II rats survived until the end of the experiment (37th day after operation). The mean growth rate curves of the two groups of animals throughout the experiment are virtually? identical (Fig. 1), and therefore the two groups areo strictly comparable in the efficiency of the thyroidec-음 tomy, food intake, and other factors influencings body weight. The mean growth curves of the rats in each cage are also parallel. As shown in Fig. 1 theres is also a suggestion of some correlation between body weight and animal house temperature. No thyroid tissue was found in any of the rats $a t$ autopsy.

Joints.-Frank arthritis, an unquestionable swell-⿳亠丷厂 ing of the joint together with redness of the overlying skin, was noticeable to the naked eye in the hind: feet of eight rats during the course of the experiment. N The arthritis was noticed first in a thyroparathyroid- $G$ ectomized and unilaterally nephrectomized rat of Group II on the 15th day of the experiment.Three more Group II rats developed arthritis in the ankle or tarsal joints (Figs 2 and 3) on the 17th day, and one other rat of this group on the 19th day. The 3 arthritic joints were warm to touch, and tender. The arthritic appearance lasted for some 3 days in all $\vec{c}$ cases and then regressed. Such an obvious arthrignse

Fig. 2.-Hind foot of rat showing arthritis in tarsal region.

Fig. 3.-Hind foot of nonarthritic rat for comparison with Fig. 2. 


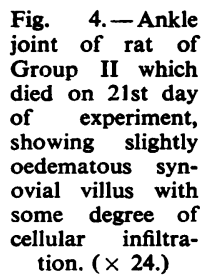

Fig. 6.-Ankle joint of Group I rat, showing proliferation and enlargement of synovial villi at termination of experiment. ( $\times 24$. $)$
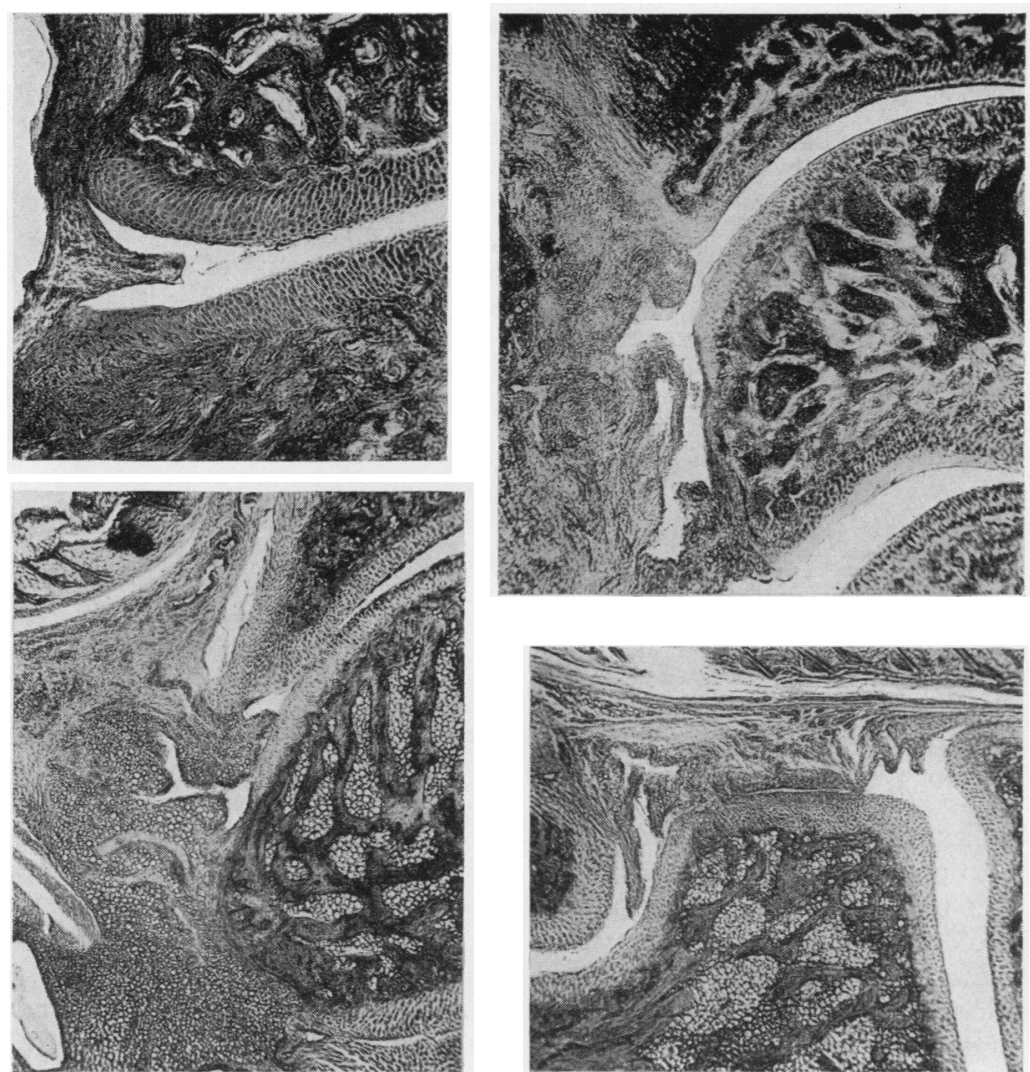

Fig. 7.-Coronal section through ankle joint of Group I rat, showing proliferation af synovial villi at end of experiment. $(\times 24$.

As early as the 21 st day after operation, cartilage did not appear in rats of Group I until the 31st-33rd days of the experiment, when three rats displayed frank arthritis in one or both hind feet exactly similar to that which occurred in the Group II rats. On the 17th-19th days of the experiment five rats of Group I and three of Group II showed appearances in their hind feet very suggestive of arthritis, with redness, tenderness, and very slight swelling of the ankle joint. At no time did arthritis develop in the fore feet of any rat.

Microscopically the joints of the hind feet of all rats of both groups killed from the 19th day of the experiment onwards were very similar in appearance to the human rheumatoid type of arthritis. All grades of synovial involvement could be found, from slight proliferation and hyperaemia on the 21st day (Figs 4 and 5) to definite enlargement, proliferation, and cellular infiltration of the synovial villi (Figs 6 and 7) in all rats of both groups killed at the end of the experiment. The histological signs of arthritis in the joints of the two groups did not differ in the same way as the time of onset of macroscopic lesions. In general, the later in the experiment the rat was killed, the more severe the joint involvement. cells in the superficial layers of articular cartilage showed marked degeneration (Fig. 8), and the cells in the articular cartilage of all arthritic joints contained prominent pleomorphic basophilic bodies (Fig. 9, overleaf), which might become extracellular towards the superficial surface of the

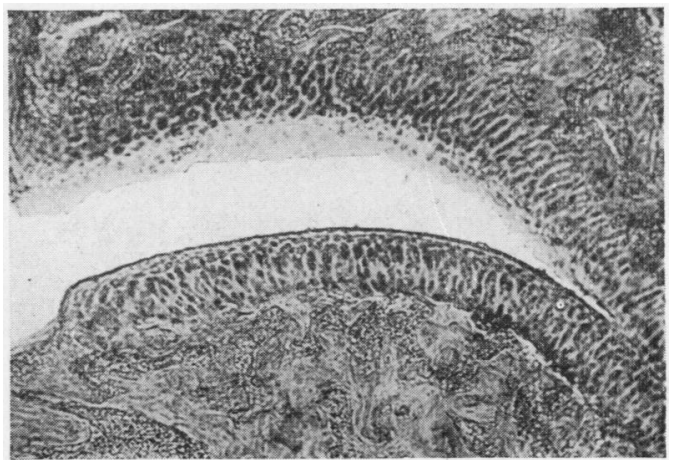

Fig. 8.-Degeneration of cartilage cells in superficial layers of articular cartilage at lower end of tibia (top) in rat killed on 21 st day of experiment. Normal articular cartilage covering upper surface of talus can be seen in lower part of figure. $(x$ 53.) 


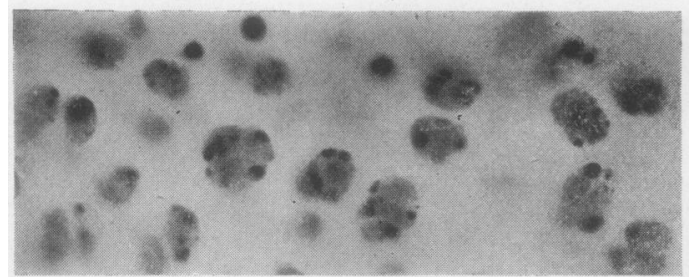

Fig. 9.-Intracellular basophilic bodies in cells of articular cartilage at lower end of tibia of Group I rat killed at end of experiment. $(\times 460$.

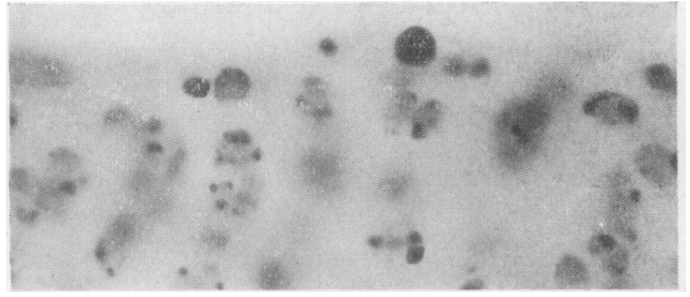

Fig. 10.-Surface of articular cartilage at lower end of tibia of Group I rat killed at end of experiment. A "pyknotic sphere" may be seen being extruded from surface of cartilage in upper part of figure. Cartilage celle contain basophilic bodies. $(\times 460$.

cartilage. Such bodies are difficult of explanation; they are too large to be virus inclusion bodies, and too pleomorphic to be bacteria, even the pleuropneumonia group of organisms. These bodies may occasionally be found in the joint space, sometimes with larger pyknotic spheres (Fig. 10), very similar to the structures found in the seminiferous tubules of the rat testis following ischaemia (Oettlé and Harrison, 1952). The joint cavity was never found to contain leucocytes as in previous experiments (Harrison, 1951a), bacteria, or large accumulations 3 of joint fluid. In many joints the synovial membrane므. encroached on to the surface of the periphery of the? articular cartilage (Fig. 11); in other joints definite $\overrightarrow{\vec{F}}$ premonitory signs of erosion were noticed; in one ankle joint a definite erosion occurred (Fig. 12). 등 Changes suggestive of derangement of the epiphyseal $\frac{\bar{c}}{\circ}$ cartilage, and even decalcification and slight $\overrightarrow{\mathbb{D}}^{\vec{\alpha}}$ absorption of some phalangeal elements, could be seen. In one rat a granuloma involving the peri- $\infty$ osteum of a metatarsal (Fig. 13) was a notable $\overrightarrow{0}$ feature.

Adrenals. - Unlike previous experiments (Harrison, 1951a), neither the gross histological nor the histochemical appearances of the adrenal cortex gave any assessment of the state of its secretory activity in? relation to the arthritic process. This is due to two is features. First, since the animals which died or were of killed during the course of the experiment had a lungo infection, the adrenal cortices of such rats were invariably hypertrophied, and can only be considered $\square$ as reflecting the response to infection; secondly, the interval between the occurrence of macroscopic $\frac{\mathbb{S}}{3}$ signs of arthritis and the termination of the experiment varied in different rats in the two groups. Thus, the adrenal of a rat dying on the seventh day of thes experiment (Fig. 14), although large, is not 6 markedly hypertrophied, nor as sudanophilic, as thatio of a rat killed on the 21 st day of the experimentt (Fig. 15) immediately after the occurrence of arthritis on 2 successive days. There is little difference⿳亠丷厂
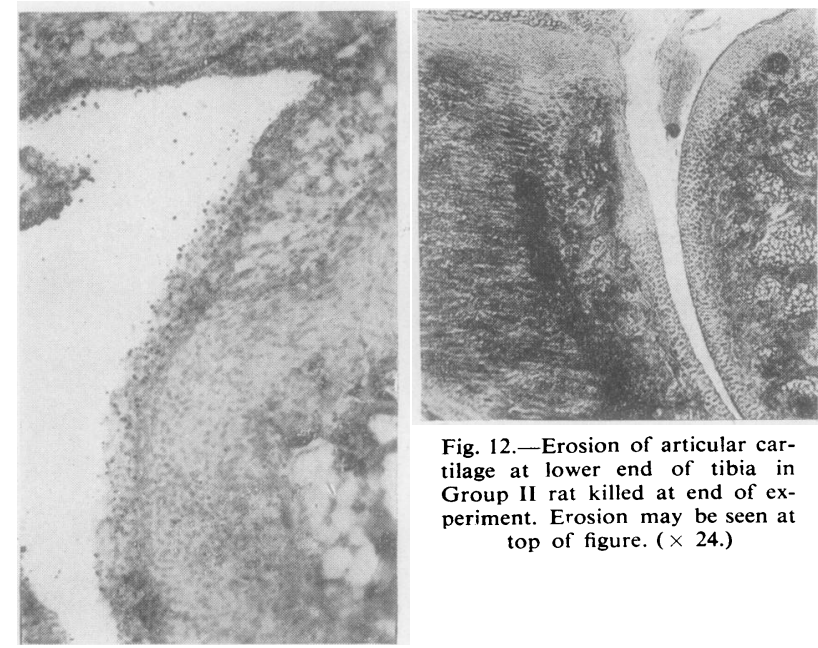

Fig. 12.-Erosion of articular cartilage at lower end of tibia in Group II rat killed at end of experiment. Erosion may be seen at top of figure. $(\times 24$.

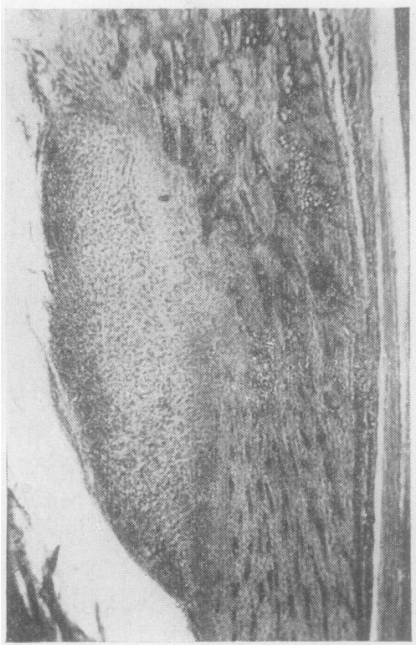

Fig. 13-Granuloma involving periosteum of metatarsal of Group II rat killed at end of experiment. tarsal of Group II rat killed face at periphery of articular cartilage at lower end of tibia in Group II rat killed at end of experiment. $(\times 83$. 
Fig. 14.-Adrenal cortex of Group II rat which died on 7 th day of experiment. Sudan black coloration not very dense. $(\times 9$.)
Fig. 15.-Adrenal cortex of Group II ment after occurrence of arthritis on two successive days. Sudan black more marked at periphery of $z$. fasciculata, and adrenal larger than in Fig. 14. $(\times 9$. rat which died on 21 st day of experi-

Fig. 16.-Adrenal cortex of Group II rat killed at end of experiment, which had macroscopic arthritis on 17th day. Sudanophilia more marked than in Figs 14 and 15. $(\times 9$.

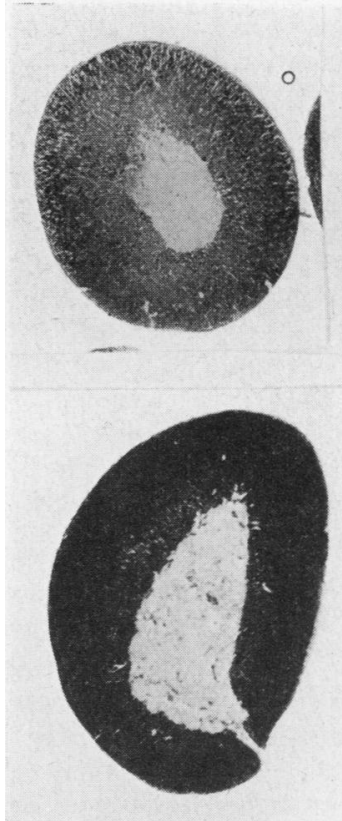

Fig. 17.-Adrenal cortex of Group II rat, killed at end of experiment, which had no macroscopic evidence of arthritis. Adrenal is slightly larger and more markedly sudanophilic than that in Fig. 16. Sudan black. ( $\%$ 9.)

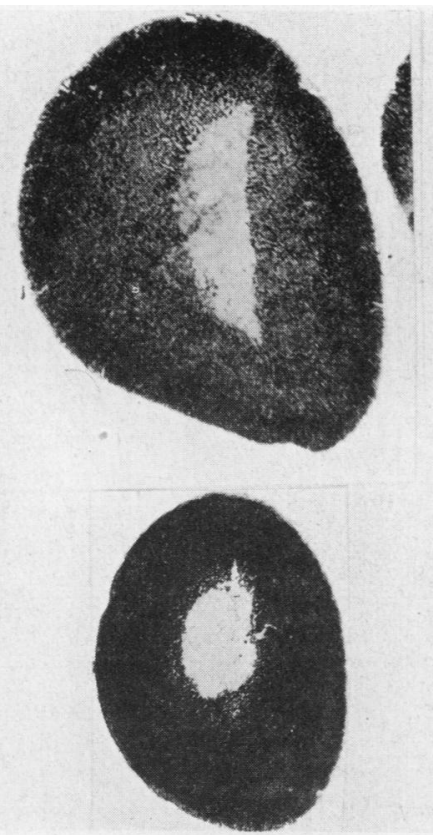

Fig. 18.-Adrenal cortex of Group I rat, killed at end of experiment, which had no macroscopic evidence of arthritis. Adrenal is abo't the same size as that in Fig. 16, but cortex more uniformly sudanophilic. Sudan black. $(\times 9$.
Fig. 19.-Adrenal of Group I rat, killed at end of experiment, which had no macroscopic evidence of arthritis. Although this rat was similar to that in Fig. 18, the adrenal is smaller, and its zona reticularis less well marked. Sudan black. ( $\because 9$.)

between the adrenal cortices of two rats of Group II which survived to the end of the experiment: one (Fig. 16) had macroscopic signs of arthritis on the 17 th day of the experiment, and the other (Fig. 17) had no such signs, but both, of course, showed microscopic arthritis at the end of the experiment; but it may be noticed that the adrenal in the latter is slightly larger and its cortex more markedly sudanophilic. Nor is there any marked difference between the adrenal cortices of these two rats, and that of one (Fig. 18) of Group I which had no macroscopic arthritis throughout the experiment, though histological signs of arthritis were found at autopsy. Yet the adrenals of another rat of Group I similar in body weight and experimental behaviour to the latter, were much smaller and had a less marked z. reticularis (Fig. 19). It may be noted, however, that the adrenal cortex in all rats killed at the end of the experiment was more markedly sudanophilic than in the two rats killed on the 7 th and 21 st days of the experiment.
The distribution of phospholipid in adrenals of the two groups (Figs 20 and 21, overleaf) is also virtually identical and independent of the presence of arthritis. Although there was no histological appearance of the adrenal cortex in these experiments which could be identified with the occurrence of arthritis, it must be stressed that the histology of the adrenal cortex at the time of onset of the arthritis will obviously give a true picture of its status at that time, and there was no opportunity of such an examination in this experiment in a rat free from the complication of lung infection. Even experimental focal necrosis of the adrenal cortex, which may be a factor in the aetiology of arthritis in rats, can be detected only in its early stages (Harrison, 1951a). Nevertheless, there was a suggestion of diminution in width of the adrenal cortex of many rats in this experimental series, as has been described in thyroparathyroidectomized rats by Deane and Greep (1947). The z. glomerulosa in all rats of both groups showed diminution in lipoid and phospholipid content which 


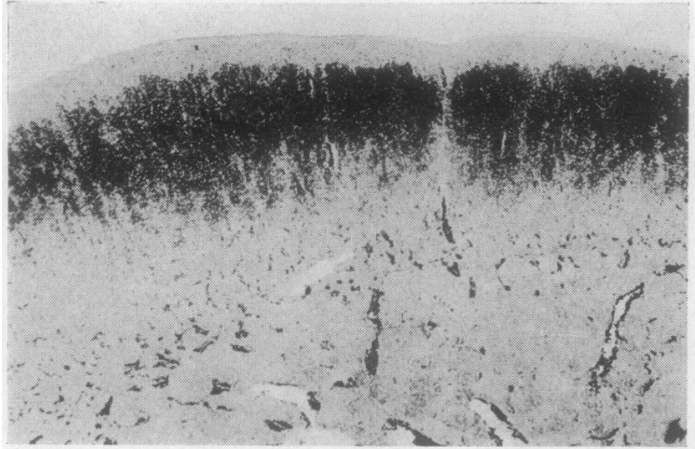

Fig. 20.-Distribution of phospholipid in adrenal cortex of Group I rat. Note absence of coloration in zona glomerulosa. Phospholipid confined to outer zona fasciculata. $(\times 40$.)

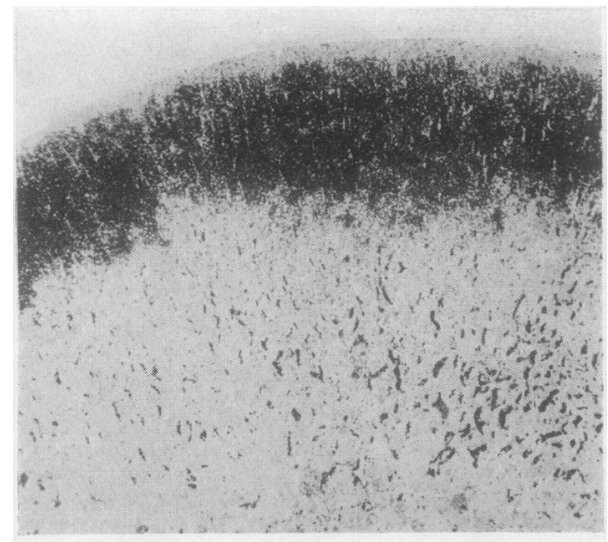

Fig. 21.- Phospholipid in adrenal cortex of Group II rat similar in experimental behaviour to that in Fig. 20. Distribution of phospholipid almost identical. Wider adrenal cortex accounted for by differences in body weight of animals at autopsy. ( $\times 40$.)

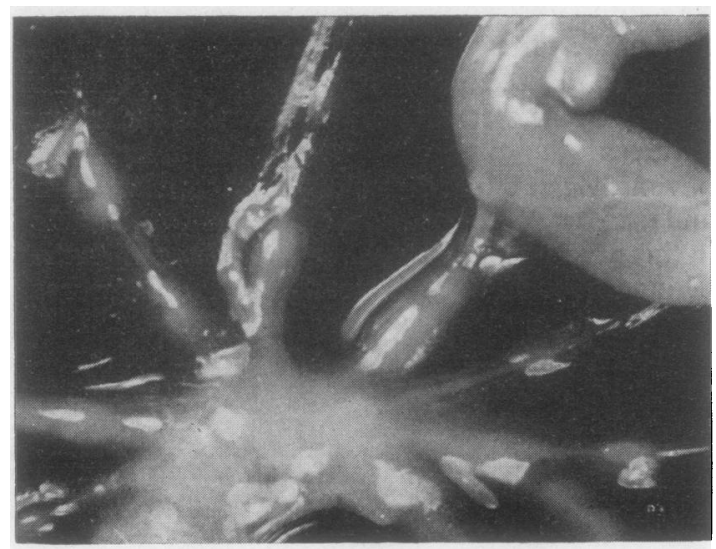

Fig. 22.-Nodules of periarteritis in mesentery of Group II rat killed at end of experiment. was due to the DCA treatment, but several rats did not show complete depletion of this zone, possibly because thyroparathyroidectomy itself causes increased lipoid content in this zone (Deane and Greep, 1947). There was no focal necrosis in the adrenal cortices of any of the rats used in this experiment, which confirms the avoidance of damage to inferior adrenal arteries during the nephrectomy at operation in Group II rats.

Heart, Kidneys, and Mesentery. - The histological appearances of the hearts and kidneys of all rats are within normal limits, and no pathological processes such as nephrosclerosis, Aschoff bodies, or Anitschkow myocytes could be found. If the conclusions of Harrison (1952) be accepted, it is therefore improbable that the adrenals in the rats of this experiment are normal. In one Group II rat gross and microscopic signs of periarteritis nodosa were present in the mesentery (Figs 22 and 23).

\section{Discussion}

It is not possible to produce arthritis by injections of DCA in rats having normal adrenals (Harrison, 1946, 1951a, 1952). The experiments reported in thiso communication demonstrate that arthritic changes can be induced in thyroparathyroidectomized ratş by these injections. It is quite possible, therefore; that the effect of this operation on the $z$. fasciculata of the adrenal cortex may have been largely instru-

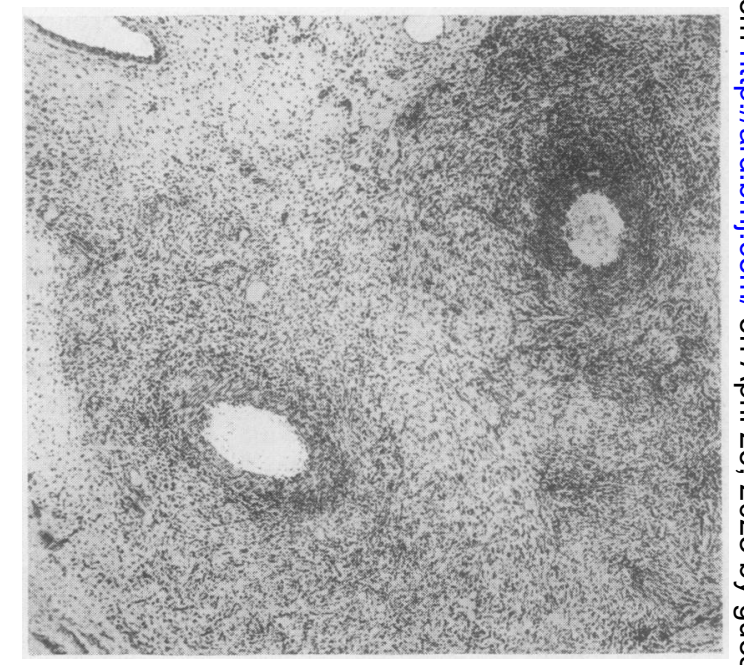

Fig. 23.-Histological appearance of periarteritis nodosa shown in Fig. 22. $(\times 39$. $)$ 
mental in the causation of the arthritis. Selye and others (1944) claimed that thyroidectomy greatly facilitated the production of joint lesions in rats injected with DCA, since they were able to obtain arthritis at room temperature in rats which were neither thyroidectomized nor adrenalectomized. In this laboratory arthritis has only been shown to occur in DCA-injected rats after thyroidectomy or adrenal cortical necrosis.

In previous experiments (Harrison, 1951a) it was claimed that unilateral nephrectomy affects the experimental production of arthritis by causing a focal necrosis of the $z$. fasciculata of the adrenal cortex. It is obvious from the present experimental series that unilateral nephrectomy not involving the adrenal blood supply is not essential for causing arthritis in the thyroparathyroidectomized rat, but there is a suggestion that it does aid the more rapid onset of macroscopic joint lesions. These experiments also demonstrate that, whereas the naked-eye appearance of arthritis is fleeting, the histological lesions in the joints are progressive in character. No leucocytes were found in the joints, as in previous experiments (Harrison, 1952) in which the arthritis was produced by adrenal cortical necrosis.

One striking feature in this investigation was the number of rats in Group II which became moribund with pneumonitis or pneumonia during the course of the experiment. This was not seen in any of the Group I rats, although they were in cages in close proximity to those of Group II. The two groups differ only in the unilateral nephrectomy performed in the Group II rats, and it is possible that this may have been an aetiological factor in the pulmonary lesions, perhaps through the mechanism of fluid imbalance, particularly since many of the Group II rats developed ascites at some point during the experiment. Since unilaterally nephrectomized rats in previous experiments have not shown pulmonary lesions, it appears that the thyroparathyroidectomy is important for their production. This confirms the relatively high incidence of pneumonia in thyroparathyroidectomized and unilaterally nephrectomized rats in the experiments of Selye and others (1944).

The importance of "stress" in experiments such as this has been over-emphasized by many authors. It has become almost customary for freak results or abnormal and unexpected findings to be labelled "probably due to stress caused by ...". As a result of this scapegoat treatment it is well not to attribute anything to "stress" which has not been carefully considered first. In this experiment the rats were killed by chloroform overdosage, and the adrenals were placed in the fixative within a few minutes. In this matter of killing experimental animals there is lack of unanimity almost to the point of hysteria; a belief that results are incomparable since one author kills rats by chloroform overdosage, and another by decapitation. Yet this is to a large extent invalid, since the adrenals of littermate rats killed simultaneously show the same picture whether chloroform overdosage, decapitation, coal gas, or nembutal overdosage is used (Cain and Harrison, 1950). It is much more important to use littermate animals, a fact often ignored.

All rats of the same group were kept together, six to a cage. The method of placing one rat to a cage was avoided since rats are sociable animals by nature, and separating them may cause as much "stress" as the small amount of fighting which occurs when the rats are together. This can readily be demonstrated by separating a rat from its littermates and then releasing it, when the animal will return to its mates and try to find a way into their cage. Other "stresses" to which the rats were subjected, e.g. subcutaneous injections, were unavoidable and minor in nature.

The experiments reported in this communication may have considerable clinical value. Most investigators report improvement of arthritis by thyroid medication only when frank hypothyroidism is present. Yet Mandl and Gyri (1952) have had considerable cortisone-like success in the treatment of arthritis by the implantation of goitrous thyroid tissue. It may well be advisable to re-investigate the relationship of thyroid hypofunction to human arthritis.

\section{Summary}

(1) Injections of DCA in the thyroparathyroidectomized albino rat produce macroscopic evidence of arthritis, which is fleeting. Microscopically the arthritis appears to be progressive in nature.

(2) Unilateral nephrectomy hastens the onset of naked-eye evidence of arthritis, but is not per se a prerequisite for the production of joint lesions.

(3) These changes are probably due to a hypofunction of the zona fasciculata of the adrenal cortex consequent on thyroparathyroidectomy.

(4) The clinical relationships and the importance of "stress" in this study are discussed.

This research was aided by a grant from the Medical Research Council. We are indebted to Dr. W. J. Tindall, Organon Laboratories Ltd., for the supplies of DCA used in these experiments, and to Lever's Cattle Foods, Ltd., Bebington, Cheshire, for manufacturing a diet similar in composition to "purina fox chow". We also wish to thank Mr. L. G. Cooper and Miss B. Birkett for their technical assistance. 


\section{REFERENCES}

Baker, J. R. (1946), Quart. J. micr. Sci., 87, 441.

Cain, A. J., and Harrison, R. G. (1950). J. Anat., Lond., 84, 196.

Deane, H. W. and Greep, R. O. (1947). Endocrinology, 41, 243.

Harrison. R. G. (1946). Lancet, i, 815.

Harrison, R. G. (1946). Lancet, 1,8

(19511a). Brit. med. J., 2, 1299.

(1951b). J. Anat., Lond, 85 ,

Mandl, F., and Gyri, W. (1952). Wien. med. Wschr., 102, 550.

Oettlé, A. G., and Harrison, R. G. (1952). J. Path. Bact., 64, 273.

Selye, H., Sylvester, O., Hall, C. E., and Leblond, C. P. (1944) J. Amer. med. Ass., 124, 201.

Arthrite provoquée par des injections d'acétate de deoxycortone chez des rats thyroparathyrö̈dectomisés

\section{RÉSUMÉ}

(1) Des injections d'acétate de deoxycortone aux rats thyroparathyroïdectomisés déclanchent des signes macroscopiques d'arthrite qui est éphémère. Microscopiquement cette arthrite semble être de nature évolutive.

(2) Une néphrectomie unilatérale accélère le début des signes d'arthrite observables à l'oeil nu, mais elle n'est pas, par elle même, une condition préalable pour produire des lésions articulaires.
(3) Ces altérations sont probablement dues à la hypofonction de la zone fasciculée de l'écorce surrénale à la suite de la thyroparathyroïdectomie.

(4) On discute les implications cliniques de cette étude et l'importance de la "fatigue".

\section{Artritis producida por inyecciones de acetato de deoxicortona en ratas tiroparatiroidectomizadas \\ SUMARIO}

(1) Inyecciones de acetato de deoxicortona en ratas tiroparatiroidectomizadas producen manifestaciones macroscópicas de artritis que es transitoria.

(2) Una nefrectomia unilateral acelera la aparición de los signos de artritis directamente observables pero no es, po si misma, una condición previa para producir lesiones articulares.

(3) Estas alteraciones se deben probablemente a la hipofunción de la zona fasciculata de la corteza suprarrenal como consecuencia de la tiroparatiroidectomia.

(4) Se discute en este estudio las implicaciones clínicas y la importancia de la "fatiga". 